\title{
Universidade: a idéia e a história
}

\author{
FRANKLIN LEOPOLDO E SILVA
}

$\mathrm{N}$

UM DOS MOMENTOS fundadores da modernidade encontramos uma atitude iconoclasta: a crítica severa que Bacon faz de todos os ídolos enquanto cristalizações naturais, morais e culturais, figuras projetadas pelo homem e às quais ele julga dever se submeter. A separação entre ciência natural e teologia em Galileu, bem como a reivindicação da liberdade da razão e a recusa da tradição, em Descartes, representam a seqüência desse processo. Podemos notar o alcance dessa última característica, que de alguma maneira engloba as demais, uma vez que a crítica da idolatria e a deliberação de pensar autonomamente naturalmente estão implicadas na recusa em aceitar qualquer critério que não se explicite nos procedimentos racionais, opção metódica que põe em xeque o próprio valor da tradição.

Tudo isso significa que, para o homem moderno, não existiria no passado nada que se pudesse entender como por si mesmo venerável, ou aquilo diante de que tivéssemos que nos inclinar em atitude de respeitosa aceitação. Isso supõe também que tal posição não é assumida gratuitamente: são os novos critérios de verdade que me alertam de que nada do que ocorreu no passado pode ser considerado intrinsecamente venerável. O peso dessa recusa é proporcional à grandiosidade da falta que ela instaura, isto é, do vazio que se segue a essa mudança radical dos eixos de equilíbrio do conhecimento e da ação. Por isso, a recusa da tradição implica um trabalho gigantesco de construção de novos conteúdos de conhecimento, de novos critérios de ação e, sobretudo, da invenção de novos parâmetros orientadores dessa atividade. O projeto humanista moderno define-se na sua base pelo ideal de construção e autoconstrução a partir da liberdade.

Formuladas assim, as coisas parecem bem simples. Trata-se de substituir a continuidade da tradição, a conservação dogmática, característica das épocas passadas, pela instauração da descontinuidade e pela abertura de um processo de sucessivas invenções e reinvenções do presente, fundamentadas nos atos livres de afirmação que definem e redefinem os rumos da teoria e da prática. Foi preciso colocar as coisas nesse grau de pureza exacerbada para provocar a situação de antítese que justificasse a radicalidade da opção moderna pela liberdade de tudo reconstruir a partir do presente, ou do enfrentamento do mundo por uma razão despojada de todas as crenças que pudessem ainda vinculá-la à tradição, comprometendo a sua autonomia. 
O passado, todavia, é em geral mais complexo do que as interpretações imediatas que dele se fazem a partir do presente, ainda mais se tais interpretações forem orientadas pela vontade de afirmação do presente diante da tradição. Nessa situação, inevitavelmente exagerada, a oposição que se faz ao passado oculta as oposições internas desse mesmo passado que, se devidamente consideradas, nos impediriam de nivelá-lo para produzir uma visão uniforme e homogênea. Certamente o passado da modernidade não se configura como a continuidade pacífica de uma transmissão de conteúdos e formas de modo absolutamente inalterável. Isso seria impossível sob todos os aspectos: material, social, cultural etc. Mas talvez toda mudança que se quer significativa exija que o presente construa uma visão que o oponha drasticamente ao passado, e assim seria natural que essa oposição fornecesse os critérios que deveriam prevalecer na diferenciação.

Essas considerações introdutórias têm o objetivo de situar o nosso problema. Quando nos voltamos para a história da universidade, para o seu passado, o objetivo é sempre a compreensão do presente. Mesmo no historiador profissional, que almeja uma visão a mais objetiva possível do passado, descomprometida com qualquer outra meta além do conhecimento, a atualidade, sendo sempre o lugar de onde fala e a partir de onde se dirige ao passado, não pode deixar de aparecer como critério orientador e, mesmo, de termo de medida da compreensão que se pretende alcançar. Isso está presente em todos os estudos sobre a universidade, desde os historicamente mais abrangentes até os mais pontuais, e a causa disso é simplesmente a impossibilidade de nos desligarmos do nosso presente. Ora, para considerar todas as conseqüências dessa impossibilidade, é importante compreender o presente como o estágio transitório entre a carga do passado e a expectativa do futuro. Assim, a valorização do presente coincide, queiramos ou não, com a sua extrema relatividade. E isso pela mera razão de que os indivíduos e as instituições são produtos históricos envolvidos no processo de construção de outros produtos históricos. Se essa transitoriedade histórica nos constitui e constitui tudo que fazemos, a precaução elementar, tantas vezes repetida, é a de evitar a consideração do que somos e do que fazemos, de nossas ações e de seus resultados, como absoluto. Sendo a produção histórica de nós mesmos e de nossas instituições um processo, não cabe entendê-la como natural e inevitavelmente dada.

E, no entanto, não há nada mais comum do que confundir, nas análises que se fazem da universidade, processo histórico e natureza dada, transitoriedade do tempo e natureza essencial da instituição. Isso não significa propriamente ignorar a relatividade histórica da universidade tal como a temos; todos provavelmente concordariam que ela é um produto histórico. Mas o que se deixa de relativizar é o percurso histórico que levou a um determinado perfil assumido pela instituição. Esse, principalmente nos tempos atuais, é visto em suas linhas gerais como inevitável, natural e necessário. E assim, esbarramos na contradição existente entre a consideração de um processo histórico contingente e o advento de instituições e de organizações que necessariamente devem ser como são. E 
isso muitas vezes leva a confundir a idéia de universidade vigente com a idéia própria de universidade.

Sem aprofundar as causas desse fenômeno, creio que podemos apontar pelo menos uma de suas razões: a noção de progresso. Quando acreditamos que há um progresso contínuo da civilização, e que as mudanças em todos os aspectos da vida, inclusive no que concerne às instituições, são resultado natural desse progresso, somos levados a entender que a experiência do presente, na medida em que é resultado histórico de um processo que é ao mesmo tempo um progresso, está constituída pelas formas mais aprimoradas da vida individual, coletiva, social, cultural e política. Caso contrário, seria o próprio vetor de civilização que estaria posto em questão. Afinal, projetamos na construção humanista da civilização moderna algo muito semelhante àquela visão retrospectiva do passado, que mencionamos há pouco. Assim como víamos uma transmissão inalterada da tradição no passado, assim também julgamos que há um vetor único na construção moderna da civilização: o progresso, fruto da libertação da tradição, a qual já não estamos obrigados a repetir. Assim, é a invenção do novo que constitui o eixo da nossa história, e a sucessão das inovações se define como progresso. É comum ouvirmos dizer, por exemplo, que mesmo as crises nada mais são do que o parto que dá nascimento ao novo, continuando sempre a trajetória de progresso.

Esse modo de considerar as coisas possui duas marcas indissociáveis: ao mesmo tempo que pretende ser um conhecimento, é também um juízo de valor. Pois, se aquilo que conhecemos como resultado histórico é também, e inseparavelmente, fruto do progresso, qualquer coisa que se viesse a pensar alternativamente seria o contrário do progresso, seria retrocesso. Isso redunda na conseqüência bem conhecida e cotidianamente sentida em nossos dias: a naturalização da história, a naturalização da vida. Tudo é como deveria ser e é insensato pensar que poderia ser de outra maneira. O progresso consiste em incorporar o presente, dado natural da realidade, e prosseguir, isto é, progredir, segundo as direções já assinaladas nessa incorporação. Progredir não significa de fato procurar outra coisa, mas aprofundar e aprimorar o que já existe, uma vez que tudo que vem a existir é devido a um progresso natural, intrínseco à pretensa inventividade moderna, à decantada autonomia que se teria conquistado na teoria e na prática. Certamente é uma contradição entender que o progresso consiste na manutenção e aprofundamento do que já existe. Mas assim como os fundadores da modernidade não puderam ver as oposições e as contradições internas ao passado histórico, assim também nós, que fazemos a experiência da modernidade como enaltecimento do presente, não podemos - e não queremos - ver as oposições e as contradições internas à nossa experiência. Crer no progresso e utilizálo como justificativa é uma estratégia para viver o presente e projetar o futuro com relativa segurança, pelo menos até que tenhamos de enfrentar o desmentido do progresso por parte dos próprios fatos que acreditávamos engendrados por ele. 
Talvez isso nos faça entender algumas tendências que atualmente procuram explicar o que se poderia chamar de "mal-estar da universidade", desde aquelas que buscam as razões do fenômeno até aquelas que vêem nele equívocos ou mesmo outras que simplesmente o negam. Concentremo-nos nessas últimas, até porque parece ser a atitude mais comum em nossos dias. Com efeito, muitos entendem que o diagnóstico desse mal-estar nada teria a ver com a realidade, mas seria antes um sintoma de veneração, no sentido que mencionamos há pouco. Algo como uma nostalgia de um certo caráter vetusto que a universidade teria perdido em razão das relações que teve de estabelecer com a sociedade contemporânea. Em outros termos, passadismo, talvez a mágoa pela perda de um caráter igualmente nobre da atividade universitária e daqueles que a exercem. A partir disso se formaria então uma idéia de universidade, calcada no passado, por vezes até remoto, que se desejaria por força conservar, ignorando as mudanças históricas e os novos modos de inserção social da instituição. Haveria aí, portanto, uma falta de visão histórico-política que estaria por trás do "corporativismo", cuja raiz seria algo como uma superestimativa do passado que se expressaria numa certa recusa do presente. Assim, o diagnóstico do mal-estar seria simples conseqüência de corações nostálgicos aprisionados no interior de uma idéia fixa e a-histórica de universidade.

O problema com que nos defrontamos para responder a essa censura, que na verdade é uma acusação, provém de que a única maneira de mostrar o seu caráter infundado seria exatamente debruçar-se sobre o passado e tentar compreender, historicamente, o que foi a universidade em outros tempos. Como em geral se considera que isso é inútil, a resposta que se encaminhe nessa direção será considerada inócua. E já sabemos a razão: como a história é sempre história do progresso, na história da universidade colheríamos no máximo informações eruditas de como se chegou à universidade fruto do progresso, e o resultado interessa muito mais do que o decurso histórico que o engendrou. Entretanto, se dedicássemos alguma atenção ao passado da universidade, olhando-o criticamente, não encontraríamos nada de vetusto, nem de enobrecedor, nem de demasiadamente conspícuo, isto é, não encontraríamos nada de uma elite corporativa que pairasse acima da sociedade e da história. O que vemos, de fato, é o mesmo que encontramos em todas as realidades humanas. A tentativa de criação, que passa por inumeráveis contradições, de um modo novo de construir o saber e os critérios de conduta social e histórica. E na realização dessa tarefa, o confronto com a tradição, com o presente, com o poder, com as outras instituições e com todas as injunções e contingências que pesam sobre a teoria e a prática.

Não podemos aqui mostrar com algum grau de pormenor factual esse caminho marcado pelas contradições próprias da vida histórica. Limitemo-nos a apontar que, desde a origem, a universidade esteve mergulhada em dilemas criados por ela mesma e pelo seu contexto. A dificuldade de transitar pela contradição que se estabelece entre a formação de uma consciência corporativa e uma consciência pública esteve desde o início presente, pela própria necessidade de se 
afirmar, ao mesmo tempo, a singularidade e a pretensão de universalidade, ou, talvez dizendo mais apropriadamente, a construção da universalidade pela via de uma criação cultural singular que teria de se integrar nas condições objetivas de sua época sem perder o perfil específico. Como resolver essa dicotomia derivada de uma dupla necessidade: recriar a sua época sendo ao mesmo tempo uma criação de seu tempo? Trata-se de uma contradição constitutiva, que se expressa em inúmeros conflitos e em outras tantas conciliações com os poderes eclesiástico e civil, assim como se expressa também na afirmação de um perfil unitário de trabalho do pensamento, o que tem de ser feito em meio às solicitações múltiplas e contraditórias da vida histórica e política.

A visão utilitária da universidade por parte das religiões e do Estado ante a autonomia como condição do avanço do conhecimento é outro modo de confronto histórico, exacerbado quando o próprio conhecimento diz respeito a crenças religiosas e a razões de estado. A vinculação clerical e a liberdade de pensamento; o patrocínio estatal e a autonomia inerente ao processo de conhecer: contradições que atravessam a vida individual e coletiva da universidade, nascida à sombra de poderes que ela estava inevitavelmente destinada a questionar. Se sobrevoarmos de muito alto a história, arriscamo-nos a ver de modo impreciso o processo histórico de constituição da instituição, que seria apenas o estabelecimento progressivo das relações diferenciadas entre a universidade e os poderes, ou entre a universidade e a sociedade. Se procurarmos uma aproximação mais concreta, observaremos a dramaticidade envolvida nessa gênese, que é a mesma presente em todo processo histórico e social de criação de realidades. A submissão à Igreja, a vinculação ao Estado, as respostas às solicitações sociais, a própria inserção histórica, nada disso se presta a análises conclusivas e a conseqüências que pudessem ser deduzidas de modo claro e definitivo.

Assim, o que teríamos de considerar, no propósito de compreender mais concretamente a universidade, é a complexidade da experiência histórica da qual a realidade presente é inseparável se quisermos compreender o presente também como experiência histórica. E aqui se situa o aspecto principal de uma visão crítica que recusa considerar a universidade apenas como um resultado histórico do progresso, algo naturalmente dado e obrigatoriamente aceito. Pois, se a história é feita de contradições e contingências, não se pode considerar nenhuma realidade histórica como o simples efeito de uma causalidade linear, como se fosse um processo físico. Se não compreendermos a experiência real pela qual a universidade se constituiu, não compreenderemos a nossa experiência de universidade. Não se trata de explicar uma coisa, mas de compreender uma história. Há, portanto, um dinamismo intrínseco na "idéia" de universidade, que não pode ser confundido com um ideal ou uma essência mais ou menos realizada na efetividade histórica. A idéia de universidade se constrói através daquilo que nela se conserva e daquilo que nela se transforma. E é exatamente por conta dessa duplicidade que a compreensão da experiência presente não pode abandonar o entendimento da experiência passada. 
Cortesia Acervo MAC-USP

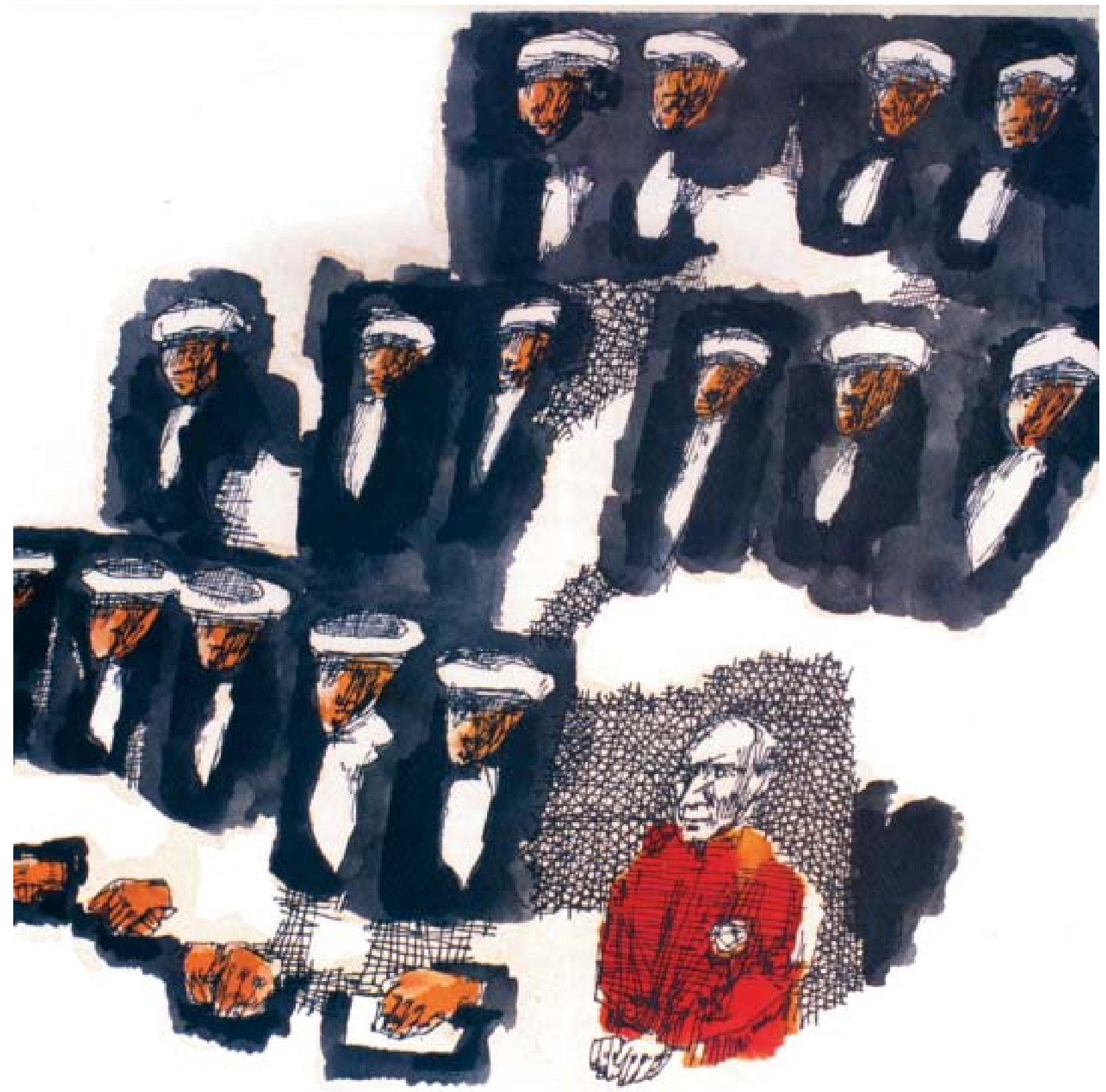

Aquarela do artista Poty Lazzarotto sobre a vida universitária. 
Por isso, não podemos partir de uma realidade dada, cuja própria consolidação já apontaria os caminhos do futuro, em inelutável continuidade com o presente. Essa aceitação significaria trair algo que está no próprio núcleo do trabalho universitário: se não colocamos a própria universidade em questão, que sentido teria colocar em questão qualquer outra coisa a partir da universidade, isto é, a partir de uma certa inserção histórica e cultural que se expressa numa determinada maneira de investigar, de criticar, de conhecer e mesmo de propor condutas? Se aceitarmos o nosso próprio status quo como irrevogável e inevitável, se é apenas a partir disso que nos é dado experimentar que devemos compreender todas as possibilidades de experiência, que legitimidade teríamos para questionar qualquer estado de coisas, sob qualquer aspecto? Afinal, todos concordamos (ainda que para alguns isso seja mera retórica) que a busca do saber é movida por uma inquietação intrínseca ao próprio movimento do conhecer. Se nos damos ao trabalho de observar um pouco mais de perto a atividade universitária nos séculos XII e XIII, isto é, no momento em que o caráter teocrático da organização sociedade e a hegemonia da Igreja eram inquestionáveis, percebemos que ainda assim não se poderia descrever a conduta de todos os membros da instituição nos termos de uma pura e simples adaptação. A relação política entre a universidade e a Igreja, entre a universidade e os estados, entre a universidade e as outras instituições religiosas e laicas já era nesse tempo marcada por uma certa tensão. Costuma-se a esse respeito citar o caso de Abelardo, mas podemos também lembrar que o próprio Tomás de Aquino, que haveria de se transformar no mais autêntico símbolo de ortodoxia, não esteve isento de suspeição, e alguns de seus escritos chegaram a ser proibidos por algum tempo. A efervescência cultural das universidades de Paris, de Pádua, de Bolonha comportava o risco inerente à dupla tarefa de construir limites sempre ultrapassando-os por via da diversidade e do aprofundamento das questões, afetadas pelo delicado liame entre verdade racional e verdade religiosa.

Se nos voltarmos para a recomposição da idéia de universidade na época moderna, no século XIX, por exemplo, veremos que nas concepções de Fichte, de Humboldt e de outros autores do período persiste a tensão inerente à necessidade de compatibilizar a expansão indefinida da liberdade de pensar com um certo ordenamento de caráter político, jurídico e mesmo simplesmente escolar. O problema comum a todos os ideólogos do sistema universitário de então era o de delimitar e definir, dentro de certos parâmetros e de acordo com a precisão possível, uma atividade que dependia tanto da total abertura de horizontes quanto de uma especificação que a qualificasse e determinasse o seu alcance e o seu valor. Não é por outro motivo que a construção de todos esses projetos de universidade se dá através da crítica do sistema existente, do ponto de vista interno, e da crítica das injunções que pesam sobre a instituição, mercê de sua necessária vinculação a outros poderes institucionais. Por mais formais que sejam esses projetos, neles está sempre presente, de forma mais ou menos explícita, a análise ético-política de fatores internos e externos, análise essa que constrói os instru- 
mentos que deverão produzir o equilíbrio intra-institucional e da instituição com seu entorno social, político e histórico. A divisão do saber, a hierarquização, as relações recíprocas, os vínculos entre o saber e o seu ensino, entre a produção do conhecimento e a sua transmissão, a centralização e a descentralização são questões totalmente atravessadas pela reflexão acerca do lugar histórico-político que a instituição deve ocupar, o qual definirá seu perfil institucional e as conseqüências quanto à dialética que deverá governar a relação entre a autonomia e os laços com a exterioridade.

Trata-se de tensões próprias ao trabalho da construção de uma universalidade real no contexto de limites formais presentes em todos os campos da realidade social. Mesmo o projeto mais idealista, se por sua origem se encontra cravado no solo das necessidades humanas, deverá inscrever-se de alguma forma no realismo das possibilidades de sua efetivação, ainda que a ambição que o impulsiona exija muitas vezes que tais possibilidades sejam pensadas nos limites da utopia. Renunciar a essa atitude será sempre diminuir por antecipação o alcance da experiência. A idealização, tanto em teoria quanto na prática, pode certamente projetar a fantasia, mas antes de tudo envolve o risco inerente ao ato de lançar-se para a consecução de objetivos dos quais só estaremos absolutamente certos quando os alcançarmos, superando a possibilidade sempre existente do fracasso.

E é a interdição absoluta do fracasso, imposta pelos critérios de eficácia racional orientadores da nossa contemporaneidade, que faz que nos recusemos a correr os riscos e que deixemos tudo por conta da pressuposta eficácia natural do progresso. Do ponto de vista subjetivo, mas com profundas repercussões no comportamento coletivo, esse deixar-se conduzir pela mão invisível do progresso implica a adoção de critérios de racionalidade instrumental e competitiva. $O$ caráter arrojado dessa atitude é apenas aparente: cremos firmemente que, se acompanharmos o progresso, não correremos riscos; essa é a razão pela qual nos alienamos e alienamos nosso trabalho ao ritmo próprio da racionalidade técnica e à expansão totalitária da tecnociência. Quando a universidade medieval comportava em seu meio aqueles a quem o conhecimento conduzia às fronteiras da heresia, muitas vezes sustentando-os e comprometendo-se com eles, ela corria seus próprios riscos. Quando a universidade contemporânea aliena sua autonomia real a mecanismos externos, muitos dos quais ela já entronizou e por isso fazem parte dela, como ortodoxia adotada, ela corre o risco mínimo do sistema que lhe é imposto ou aquele no qual ela optou por livremente se instalar. Daí a tendência à regularização homogênea, à uniformidade e à unilateralidade. Daí também a tendência à conciliação e à incorporação do pensamento único, o desprezo da diferença no qual se inscreve o esquecimento da tradição.

É nesse sentido que se pode afirmar que a universidade contemporânea não busca redefinir-se para fazer face às novas situações trazidas pela necessidade de situar-se na modernidade, e nas variadas facetas de sua dramaticidade. O que a universidade menos procura é redefinir-se; busca, isso sim, o meio mais adequado de aplicar a si mesma uma definição construída pelo tempo histórico e por 
um conjunto de idéias que se constitui pela exclusão de tudo aquilo que a universidade já instituiu e preservou como valor, ao longo de sua história. O procedimento pelo qual a universidade se redefine contemporaneamente coincide inteiramente com a sua adaptação às exigências do tempo histórico: mercado, tecnociência, organização eficaz e tecnicismo produtivista. A partir dessa pauta imposta de fora, a universidade busca refazer a sua identidade através de um processo de desinstitucionalização. Tudo o que a universidade precisa fazer é recusar o que tem sido para tornar-se o que o tempo histórico lhe impõe como um dever-ser. Nesse processo de desinstitucionalização se inscrevem vários fenômenos imediatamente presentes, tais como heteronomia (absorção de critérios extrínsecos como paradigmas do modo de ser, da organização e da gestão da universidade), a privatização (assimilação dos mecanismos neoliberais de destruição da esfera pública) e subordinação ao mercado (entronização de critérios ligados ao tecnocratismo economicista). Tais exemplos configuram o quadro da adaptação, que seria ao mesmo tempo o abandono do perfil institucional em prol do perfil organizacional.

Para tratar o assunto de modo mais próximo da nossa realidade, seria adequado estabelecer as mediações que nos levassem à compreensão do percurso histórico da universidade na América Latina, especialmente no que se refere ao período compreendido em torno dos últimos cinqüenta anos, caracterizado em várias partes do continente pelo fenômeno da ditadura. Não podemos fazê-lo, mas é lícito afirmar, a partir de análises que já foram efetuadas, que as ditaduras prepararam o caminho para o neoliberalismo e suas conseqüências, notadamente no campo social. Essa preparação ocorreu através da desarticulação da esfera pública, da restrição de direitos e da despolitização. Ao final dos períodos ditatoriais, os governos eleitos de modo formalmente democrático se viram ao mesmo tempo diante da necessidade de reconstrução democrática e dos imperativos decorrentes da globalização, expressos principalmente na ingerência de organismos internacionais na gestão da política econômica e, por extensão, na concepção e implementação de políticas públicas. Não é o caso aqui de nos estendermos sobre a questão, mas é possível avançar o diagnóstico do desaparecimento das políticas públicas pautadas pela consideração autônoma das necessidades e carências sociais, e pela sua substituição por investimentos sociais com caráter assistemático e totalmente dependentes da tutela dos gestores da economia. Essa subordinação do público ao econômico retira da esfera das políticas sociais a autonomia decisória. A educação sofre as conseqüências que conhecemos muito bem.

Restam os investimentos ocasionais no campo do social. A proposta de reforma universitária que está em tramitação é bem representativa dessa situação. Primeiramente, está fora de questão o fortalecimento da instituição universitária; cuida-se apenas de modificações organizacionais, embora muitas delas tenham repercussão significativa na esfera acadêmica propriamente dita. Isso significa que o caráter acadêmico que deveria ser assegurado pelo perfil institucional 
passa a subordinar-se aos aspectos de organização e gestão. A compra de vagas de escolas particulares como meio de ampliação do acesso (Prouni) vincula-se de modo claro à opção pelas organizações empresariais, o que reforça o efeito do enfraquecimento da instituição pública. Com isso o governo incrementa, também, o desequilíbrio quantitativo entre alunos matriculados nas universidades públicas e nas empresas privadas de ensino. A ampliação do acesso será também a ampliação de diplomados em cursos superiores. Como na maioria das universidades privadas o único requisito para se chegar ao fim do curso e receber o diploma é manter as mensalidades em dia, a compra das vagas equivale de fato à compra dos diplomas. Assim o governo garante o acesso, a manutenção do aluno na escola, e o diploma. Promessas a serem cumpridas por via da utilização da educação superior como moeda de troca com índices de popularidade e votos. Não entra em conta nem sequer o treinamento de habilidades e competências, quanto mais o critério da formação. Assim, nem mesmo a validade exclusiva da racionalidade técnico-instrumental está sendo respeitada. A proposta coloca-se, portanto, abaixo da indigência que já domina a contemporaneidade em termos de uma concepção de educação como informação e desenvolvimento de habilidades técnicas.

O que temos, assim, é uma imagem bem clara do ponto a que se pode chegar a partir de decisões de investimento sem o respaldo de deliberações políticas consistentes com a significação pública da educação. Por outro lado, nada mais coerente com a intenção de demolir a instituição universitária, encorajando a própria universidade pública a tomar como modelo o perfil mercantil da organização privada. A desvantagem quantitativa da escola pública de nível superior a encaminhará naturalmente para um regime de competição com as empresas privadas e para a assimilação desse status, agora abertamente valorizado pela própria autoridade pública. Esperávamos que o desmonte fosse mais gradual, como vinha sendo no governo anterior; resta entender as razões dessa aceleração.

Por ocasião de uma das crises do ensino superior na França, o reitor de uma das universidades francesas comparou a instituição universitária a um dinossauro pousado num aeroporto. Temos ouvido outras referências ao decantado atraso e ao perfil arcaico da universidade, em dissonância com o ritmo da civilização industrial. São diagnósticos que trazem a vantagem de uma proposta imediatamente acoplada. O sentido geral é muito claro, e bem de acordo com os tempos que correm: a universidade somente estaria à altura de seu tempo se estivesse completamente adaptada a ele. Daí a necessidade urgente de redefinila, para que ela ganhe uma identidade inteiramente calcada nas injunções do tempo histórico. E embora a universidade esteja de maneira geral operando na ponta do desenvolvimento científico no que se refere às suas pesquisas, ela não consegue o mesmo avanço quando se trata de adquirir uma consciência de si compatível com os resultados do progresso que ela mesma ajudou a criar. Assim, é preciso que essa nova identidade lhe seja outorgada, ou mesmo imposta, para abreviar o ritmo da sua atualização. E isso também porque a "corporação" man- 
teria uma certa atitude de veneração que, laicizada e vulgarizada, se confundiria com a manutenção de interesses. A proposta de um novo sistema universitário em que estejam diluídas as diferenças entre o público e o privado, e em que a organização privada prevaleça como modelo, visa acelerar o processo de adaptação, introduzindo na universidade a identidade desinstitucionalizada que ela parece estar demorando em assumir inteiramente. Seria redundante insistir nas conseqüências que esse outro perfil traz consigo, e que são conseqüências desejadas: a postura acrítica, neutra, conciliatória, utilitária, tecnicista etc.

Cabe perguntar se o eixo em torno do qual a universidade cultivou e manteve durante muito tempo, e desde as origens, seu equilíbrio instável, eixo de caráter ético, político, e mesmo lógico e cognitivo, não se define como estar sempre um pouco fora de seu tempo histórico, ao mesmo tempo enraizada nele, histórica e socialmente, mas também projetando-se para fora de seu tempo, no limite contradizendo-o, exatamente para desempenhar o seu mais importante papel, que certamente não é o de reiterar os interesses hegemônicos de seu tempo, engendrando as soluções conciliadoras por via de uma adaptação total, que, aliás, não deixaria de ser uma veneração do presente e uma venerável expectativa de futuro, mas sim o de criar as condições para que esses interesses e essa hegemonia sejam repensados como questões, e tornados temas relativos a um espaço político-institucional construído e mantido de acordo com um interesse fundamental: a liberdade da reflexão como critério ético da liberdade da ação conseqüente.

Bibliografia

AVELAR, I. Alegorias da derrota. A ficção pós-ditatorial e o trabalho do luto na América Latina. Belo Horizonte, São Paulo: Ed. UFMG, Humanitas, 2003.

CARDOSO, I. Para uma crítica do presente. São Paulo: Editora 34, 2001. . Introdução ao Dossiê “70 anos de USP”. Revista USP, n.60, dez./jan./fev. $2003 / 2004$.

CHENU, M.-D. Introduction à l'Ètude de Saint Thomas d'Aquin. Paris: Vrin, 1954.

DUPAS, G. Tensões contemporâneas entre o público e o privado. Rio de Janeiro: Paz e Terra, 2003.

FÉDOU, R. Lexique historique du Moyen-Âge. Paris: Armand Colin, 1985.

FREITAG, M. Le naufrage de l'Université. Québec, Paris: Nuit Blanche, La Découverte, 1994.

GENTILI, P. (Org.) Universidades na penumbra - Neoliberalismo e reestruturação universitária. São Paulo: Cortez, 2001.

LE GOFF, J. Para um novo conceito de Idade Média. Lisboa: Editorial Estampa, 1980. TRINDADE, H. (Org.) Universidade em ruinas na República dos professores. Petrópolis: Vozes, 2000.

VVAA. Revista Reportagem. Dossiê “Reforma Universitária”, n.56, maio 2004. 
REsUMO - O TEXTO pretende discutir aspectos da inserção sócio-histórica e política da universidade nos vários contextos históricos que marcaram a vida dessa instituição, com o objetivo de indicar que uma das características constitutivas da instituição universitária, e da forma como se construiu a sua tradição, foi estar sempre simultaneamente dentro e fora de seu tempo. Dentro, pelo aspecto institucional, no início à sombra da Igreja, depois do Estado, e, nos dias de hoje, subordinada ao mercado. Fora, pelo teor crítico que, em intensidades diferentes, pautou a atuação universitária, o que historicamente a impediu de se constituir como mero produto de seu tempo ou reflexo da hegemonia eclesial ou estatal. A questão atual, para a universidade brasileira em particular, é se ela conseguirá, ainda que parcialmente, manter-se independente das pressões de um mercantilismo onipresente, nos indivíduos e na sociedade.

PalaVRas-Chave: História, Sociedade, Crítica, Autonomia.

ABSTRACT - THE TEXT intends to discuss some relevant views of the relation between university, as institution, and the social, historical and political context. On intend to demonstrate that university has always been affected by some kind of ambiguty of his historic position, nor completely inside, nor completely out of her historical time. This double position means that Church or State, as traditional powers, never get complete control, and university, in spite of institutional caracter, never did'nt resignate her difference or critic aproach, as we may note since the Middle Ages. The question we must actually discuss concerns the possibility of the same attitude in face of Market an his omnipresent power in our time.

KErwords: History, Society, Criticism, Autonomy.

Franklin Leopoldo e Silva é professor titular do Departamento de Filosofia da Faculdade de Filosofia, Letras e Ciências Humanas (FFLCH) da Universidade de São Paulo. @-franklin@usp.br

Conferência feita pelo autor em 12 de abril de 2005 no Instituto de Estudos Avançados da USP, dentro da Temática Semestral “Os Desafios do Ensino Superior no Brasil", realizada de novembro de 2004 a abril de 2005.

Recebido em 12.4.2005 e aceito em 5.5.2005. 